\title{
A PERCEPÇÃo doS ADOLESCENTES ACERCA do ÁlCOOL E OUTRAS DROGAS NO CONTEXTO FAMILIAR
}

\author{
Maria Odete Pereira ${ }^{1}$; Silvio Silvério da Silva ${ }^{2}$; \\ Márcia Aparecida Ferreira de Oliveira ${ }^{3}$; Divane Vargas ${ }^{4}$; \\ Luciana de Almeida Colvero ${ }^{3}$; Bianca Mara Maruco Lins Leal
}

O consumo de álcool e outras drogas é cada vez mais frequente entre adolescentes. O estudo objetivou identificar a percepção dos adolescentes acerca do consumo de álcool e outras drogas no âmbito familiar. Neste estudo qualitativo empregou-se o grupo focal para a coleta de dados. Os cinco colaboradores, com idade entre 12 e 15 anos, frequentavam um centro de assistência social, vinculado a uma instituição de ensino superior, de um município do Médio Vale do Paraíba Paulista. Os relatos expressaram a percepção dos adolescentes, suas contradições e sentimentos em relação ao tema e essa percepção pautou-se em hábitos dos familiares.

Descritores: Alcoolismo; Adolescente; Preparações Farmacêuticas; Família; Políticas Públicas.

\footnotetext{
${ }^{1}$ Enfermeira, Doutor em Enfermagem, Professor, Faculdades Integradas Teresa D'Ávila, Lorena, SP, Brasil. E-mail: m.odetepereira@gmail.com.

${ }^{2}$ Engenheiro de Alimentos, Doutor em Tecnologia Bioquímico-Farmacêutica, Professor, Faculdades Integradas Teresa D'Ávila, Lorena, SP, Brasil. E-mail: silvio@debiq.eel.usp.br.

${ }^{3}$ Enfermeiras, Livre Docente, Professor Associado, Escola de Enfermagem, Universidade de São Paulo, SP, Brasil. E-mail: Márcia marciaap@usp.br, Luciana - lucix@usp.br.

${ }^{4}$ Enfermeiro, Doutor em Enfermagem, Professor Doutor, Escola de Enfermagem, Universidade de São Paulo, SP, Brasil. E-mail: divanidevargas@gmail.com.

${ }^{5}$ Enfermeira, Mestranda em Enfermagem, Escola de Enfermagem, Universidade de São Paulo, SP, Brasil. E-mail: biancammll@gmail.com.
} 


\section{The PERCEPTION OF ADOLESCENTS ABOUT ALCOHOL AND OTHER DRUGS IN THE FAMILY CONTEXT}

The consumption of alcohol and other drugs is increasingly frequent among adolescents. The study aimed to identify the perception of adolescents about the consumption of alcohol and other drugs within the family. In this qualitative study, focus groups were used to collect data. The five collaborators, between 12 and 15 years old, attended a social service center affiliated with a higher education institution in a city in the Médio Vale do Paraíba Paulista. The reports expressed the adolescents' perception, its contradictions and feelings on the theme and this perception was based on family members' habits.

Descriptors: Alcoholism; Adolescent; Pharmaceutical Preparations; Family; Public Policies.

\section{LA PERCEPCIÓN DE LOS ADOLESCENTES SOBRE EL ALCOHOL Y OTRAS DROGAS EN EL CONTEXTO DE LA FAMILIA}

El consumo de alcohol y otras drogas es cada vez más común entre los adolescentes. El objetivo del estudio fue identificar las percepciones de los adolescentes sobre el alcohol y otras drogas en la familia. En ese estudio cualitativo, grupos focales fueron usados para recoger los datos. Los cinco empleados de entre 12 y 15 años eran clientes de un centro de servicios sociales vinculado a una institución de educación superior en un municipio en el Valle Medio del Paraíba Paulista. Los informes expresaron la percepción de los adolescentes, sus contradicciones y sentimientos sobre el tema y esta percepción se basaba en los hábitos de los miembros de la familia.

Descriptores: Alcoholismo; Adolescente; Preparaciones Farmacéuticas; Familia; Políticas Públicas.

\section{Introdução}

O interesse pelo tema - a percepção dos adolescentes a respeito do álcool e outras drogas - surgiu a partir da iniciativa de extensão universitária e do Colégio de Aplicação do Ensino Fundamental e Médio, ambos vinculados à Instituição mantenedora, denominada Instituto Santa Teresa, das Redes Salesianas de Ensino, situada em um município do Vale do Paraíba Paulista. A articulação institucional busca intervir no processo educativo dos estudantes abordando várias temáticas, dentre elas, o álcool e as outras drogas.

Assim, os autores elegeram a temática para trabalharem no Colégio de Aplicação com adolescentes, uma vez que, nas últimas décadas, o consumo de substâncias psicoativas tornou-se problema de saúde pública, quando deixa de ser um uso ocasional e acarreta dependência física e psíquica.
O consumo abusivo se dá pelas variáveis: diversidade e viabilidade de aquisição, o que resulta em um número cada vez mais crescente de usuários, dentre eles adolescentes e jovens, conforme mostram estudos recentes ${ }^{(1)}$.

A utilização do álcool e outras drogas foi paulatinamente se disseminando por todas as classes sociais, tornando-se problema de grande complexidade e diversidade para os campos da economia, política, cultura e saúde, e o crescente consumo abusivo dessas substâncias traz às famílias, como centro primário de educação, o desafio de proporcionar orientação aos seus e combater a propagação em seu interior, uma vez que, mesmo sendo uma instituição privada passível de vários tipos de arranjos neste mundo pós-moderno, continua tendo a função de socialização primária das crianças e adolescentes ${ }^{(2-3)}$. 
A família, que tem por missão a preservação da espécie, alimentar, proteger, além de dar aos seus descendentes condições para a aquisição da identidade pessoal, desenvolveu, ao longo do tempo, diversificadas funções de transmissão de valores éticos, estéticos, religiosos e culturais, e deve cumprir o papel de transmitir os hábitos, costumes, ideias, valores e padrões de comportamento da sociedade $^{(4-5)}$.

A família consegue proteger a criança das influências sociais até certo período de tempo, mas não na totalidade, atestando que os registros socioculturais são fundamentais na formação do sujeito ${ }^{(6)}$. Assim, a família e as instituições socioculturais devem trabalhar em conjunto para a formação do "eu" do sujeito, podendo ser aliados ou se chocarem. Quando a família e a sociedade não conseguem se ajudar numa elaboração bem-sucedida está-se diante de possíveis situações de violência ${ }^{(7)}$.

Embora a atenção do adolescente esteja voltada para a vida social, centrada nos grupos de colegas e amigos, para compreender o que ele pensa, é necessário inserilo no contexto familiar e sociocultural, pois a família integrada à cultura é que fornece as bases para o seu desenvolvimento ${ }^{(3)}$.

Mediante esse panorama, surge um questionamento: e quando o contato inicial e/ou o consumo de substâncias psicoativas se dá no próprio ambiente familiar? $\mathrm{O}$ que pensa o adolescente? Qual a percepção dele acerca do álcool e das drogas diante dessa situação? Conhecer e analisar a percepção de adolescentes acerca da temática apresentada é de elevada relevância social, uma vez que o adolescente que entra em contato com as substâncias psicoativas em sua própria rede familiar, enquanto um ser que está passando por fase de consolidação de sua personalidade, não está recebendo formação clara e coerente, já que essa experiência doméstica se contrapõe à educação que recebe na escola, e até mesmo com os valores ditos e reconhecidos não só pela sociedade como corretos e saudáveis, mas, também, pela Organização Mundial da Saúde. Assim, o presente estudo teve por finalidade agregar conhecimento para a elaboração de estratégias no diagnóstico e intervenção precoce entre adolescentes, na luta contra a dependência de substâncias químicas.

O estudo objetivou compreender a percepção dos adolescentes acerca do álcool e outras drogas, no âmbito familiar.

\section{Material e Métodos}

O presente estudo é descritivo e empírico, de natureza qualitativa.

Os colaboradores do estudo foram cinco adolescentes, com idade entre 12 e 15 anos, vinculados a um centro de assistência social, mantido por uma instituição de ensino superior de um município do Médio Vale do Paraíba, interior do Estado de São Paulo. O número de colaboradores foi estabelecido pela saturação das respostas, por se tratar de pesquisa qualitativa.

Os critérios de inclusão foram: pertencer à faixa etária entre 12 e 15 anos, assinatura do termo de consentimento livre e esclarecido pelo responsável do participante e frequentar o referido centro de assistência, como usuário regular.

Inicialmente, a Instituição foi contatada para autorização formal à participação do estudo. O representante legal recebeu uma carta com as explicações necessárias acerca da pesquisa e assinou o termo de consentimento livre e esclarecido - TCLE. A seguir, o trabalho foi submetido e aprovado no Comitê de Ética das Faculdades Integradas Teresa D'Ávila, sob Protocolo $\mathrm{n}^{0} 52 / 2008$. O mesmo procedimento foi realizado com os responsáveis pelos colaboradores, tendo sido observadas todas as exigências da Resolução nº196/96, do Conselho Nacional de Saúde. As visitas para a coleta de dados foram agendadas com antecedência, por telefone, em dia e horário determinados pela Instituição e convenientes aos colaboradores. Os dados foram coletados por um dos autores e mais seis alunos do nono período do ensino fundamental, colaboradores do Colégio de Aplicação do Instituto Santa Teresa, já abordado anteriormente.

Para a coleta de dados foi utilizada a técnica qualitativa de grupo focal, cujo resultado visa o controle da discussão de um grupo de pessoas. Esse método possibilita a análise das percepções em uma realidade imediata, buscando o significado e os pressupostos dos fenômenos. São apropriadas para estudos que buscam entender atitudes, preferências, necessidades e sentimentos. Nessa técnica, o mais importante é a interação que se estabelece entre os colaboradores ${ }^{(1)}$.

Neste estudo, o facilitador da discussão no grupo focal foi um dos autores, em atividade de pesquisa em iniciação científica. Na perspectiva do grupo focal, o facilitador é quem estabelece e promove a discussão, mas não realiza uma entrevista em grupo. O papel do facilitador, portanto, é o de promover a participação de todos, evitando a dispersão dos objetivos da discussão e a monopolização por parte de alguns colaboradores.

Foram realizados três encontros grupais para discussão acerca do tema álcool e outras drogas no contexto familiar, com duração de, aproximadamente, 40 minutos, cada um, durante os meses de abril e junho de 2009.

Todas as narrativas e discussões foram gravadas, transcritas e transcriadas ${ }^{(8)}$. A fim de preservar a identidade dos colaboradores, os autores optaram por utilizar apenas as iniciais dos nomes dos colaboradores.

Um instrumento não estruturado com cinco questões norteou os pontos abordados nos encontros do grupo focal. Foram utilizadas perguntas conduzidas pela tríade: o quê? Para quê? Por quê? Sendo solicitado que os colaboradores exemplificassem suas ideias e buscassem aprofundar a discussão, a fim de esclarecer suas falas.

A análise dos resultados obtidos nas reuniões do grupo focal foi realizada sob a ótica do referencial filosófico fenomenológico que remete à descrição da realidade, à vivência e à experiência existente ${ }^{(9)}$.

Segundo o referencial teórico, os autores consideram as palavras utilizadas pelos colaboradores por repetidas vezes, o contexto no qual a informação foi obtida, concordâncias entre as opiniões dos colaboradores, alteração de opiniões, respostas dadas em função de experiências pessoais de maior relevância do que impressões 
vagas, ideias principais, comportamentos, gestos, reações, sentimentos, valores de ordem pedagógica, ideológica e ética, preconceitos, dificuldades de compreensão das perguntas feitas, entusiasmos e, por fim, as dificuldades para o enfrentamento de desafios, aproveitando os espaços de liberdade de expressão.

\section{Resultados e Discussão}

Primeiro encontro: "à procura de compreender os significados" os significados e as percepções acerca do uso abusivo do álcool e outras drogas, no ambiente familiar. Para tanto, utilizou-se a técnica inicial conhecida como brainstorming (explosão de ideias), motivada pela questão: qual a primeira ideia que lhe vem à mente quando se fala em álcool e outras drogas?

De acordo com as respostas, os autores observaram algumas concepções nas quais os colaboradores demonstram conhecimentos acerca do objeto de estudo, atribuindo-lhe diferentes significados, como as descritos, a seguir, na Figura 1.

O objetivo do primeiro contato foi o de investigar

\begin{tabular}{|c|c|}
\hline Categoria de análise & Falas dos colaboradores \\
\hline \multirow{10}{*}{ Compreendendo os significados } & O álcool e a droga são iguais, são drogas... mas, mesmo sabendo disso muitos usam (JB) \\
\hline & Os dois são ruins, mas é também uma forma de desinibir-se, depende de quem usa (MR) \\
\hline & São destruidores de vida e família (MT) \\
\hline & São coisas bem próximas a todos os seres humanos, que pode \\
\hline & fazer mal ou não, tem que saber usá (RS) \\
\hline & É algo bem ruim, que causa vício e dor (BP) \\
\hline & Já bebi e fumei, mas não para ficar dependendo disso (JB) \\
\hline & O problema é que não dá para saber se vai ou não ficar viciado depois (MR) \\
\hline & Se fosse bom, não seria droga (MT) \\
\hline & $\begin{array}{l}\text { A maioria se dá mal, então prefiro não correr o risco (RS) Existem coisas melhores na vida. Dá para ser feliz sem } \\
\text { isso, mas tem que ser forte para não entrar na onda }(B P)\end{array}$ \\
\hline
\end{tabular}

Figura 1 - Percepção dos adolescentes do significado do álcool e outras drogas

Embora com um pouco de dificuldade para expressar teoricamente o significado de algo presente, vivenciado no próprio cotidiano, percebeu-se que os colaboradores definiram as drogas como algo entre "o ruim e proibido", mas que poderia também ser algo bom ou não causar danos.

Quando dois dos colaboradores relatam que o álcool e as outras drogas podem causar a desinibição, podendo fazer mal ou não dependendo do uso, percebe-se que esses elementos fazem parte do convívio familiar e social deles, e que já estão tecendo seu olhar acerca da relação que os adultos com os quais convivem têm com eles. Assim, o beber socialmente pode proporcionar à pessoa um momento agradável de descontração, de desinibição, desde que saiba usar.

Segundo encontro: "como conviver com a realidade álcool e drogas em casa"

A pergunta que direcionou o segundo encontro foi: - o que você acha sobre o consumo de álcool e outras drogas por familiares ou responsáveis de famílias?

Os relatos marcaram diferentes percepções de gênero quanto ao tema, no ambiente familiar, sendo atribuídos valores como a maior liberdade dos homens e maior controle às mulheres, expressos na Figura 2, abaixo.

\begin{tabular}{|c|c|}
\hline Categoria de análise & Falas dos colaboradores \\
\hline \multirow{10}{*}{$\begin{array}{l}\text { Convivendo com a realidade do } \\
\text { álcool e drogas na família e entre } \\
\text { os amigos }\end{array}$} & Se os pais querem usar álcool e/ou outras drogas, não podem proibir os filhos (JB) \\
\hline & $\begin{array}{l}\text { Já bebi em casa com meus parentes, mas minha mãe fica brava, quer proibir, mas é pior, o que não dá é para ser } \\
\text { viciado, como tem muitos pais por aí (MR) }\end{array}$ \\
\hline & $\begin{array}{l}\text { Meu pai já me deu bebida para provar, mas minha mãe fala que se eu for por essa vida, vou acabar como meu pai, } \\
\text { e, ser pai assim, melhor não ser (MT) }\end{array}$ \\
\hline & $\begin{array}{l}\text { É como se fala: faça o que eu falo e não o que eu faço. Mas isso não é justo. Os jovens pensam: se não é bom por } \\
\text { que o pai faz? (RS) }\end{array}$ \\
\hline & É horrível ter isso em casa, bagunça a vida de todo mundo e nem parece família (BP) \\
\hline & $\begin{array}{l}\text { Meu primo era gente boa, mas não se saiu bem. Minha tia e minha mãe ficaram muito mal, mas não conversam, só } \\
\text { dizem que é ruim (JB) }\end{array}$ \\
\hline & Meu pai é o pior, eu acho, mas em casa a gente finge que é normal para não piorar a situação (MT) \\
\hline & Talvez o mundo fosse melhor se não perdêssemos as pessoas desse jeito e conversássemos abertamente (RS) \\
\hline & $\begin{array}{l}\text { A familia sofre por causa de um, meu pai dá muitos problemas, além da vergonha, eu e meus irmãos sofremos, } \\
\text { fazer o quê? (BP) }\end{array}$ \\
\hline & $\begin{array}{l}\text { Vários amigos já tão bem no meio, às vezes é chato demais pensar nisso, por isso prefiro não pensar, na maioria } \\
\text { das vezes (MR) }\end{array}$ \\
\hline
\end{tabular}

Figura 2 - Apresentação das percepções de adolescentes em relação à existência do álcool e outras drogas, na família e entre os amigos 
Os depoimentos revelaram que foi com a dependência de algum parente próximo, como, por exemplo, o pai ou o primo, que o tema começou a fazer parte da rotina da casa, mas sempre de forma obscura e velada, como discutido anteriormente.

Terceiro encontro: "como eu me vejo neste contexto"

No terceiro e último encontro realizou-se, junto com os colaboradores, uma síntese dos dois encontros anteriores e seus objetivos. Foi solicitado também que fizessem oralmente uma avaliação final, considerando, também, os sentimentos e emoções percebidas, e o que os encontros de grupo focal haviam representado para cada um (Figura 3).

\begin{tabular}{|l|l|}
\hline \multicolumn{1}{|c|}{ Categoria de análise } & \multicolumn{1}{c}{ Falas dos colaboradores } \\
\hline \multirow{4}{*}{$\begin{array}{l}\text { Como o adolescente se vê no } \\
\text { contexto do álcool e outras } \\
\text { drogas }\end{array}$} & $\begin{array}{l}\text { Eu sei que já tive minhas experiências com o álcool, mas sei que não quero levar isso para minha família, quando eu } \\
\text { tiver uma, pois não é legal, fica sem moral diante dos filhos (JB) }\end{array}$ \\
\cline { 2 - 2 } & $\begin{array}{l}\text { Não sei se minha família vai ser certinha, porque muitas vezes não sou, mas quero o melhor para ela, quando tiver que } \\
\text { acontecer (MR) }\end{array}$ \\
\cline { 2 - 2 } & Vou ser tudo o que quis que meu pai fosse e não é (MT) \\
\cline { 2 - 2 } & Não sei de amanhã, mas sei que tento fazer as coisas hoje dar certo pra quando eu for maior (RS) \\
\cline { 2 - 2 } & Nossos pais erram e a gente sofre com isso, se fazermos a mesma coisa, nossos filhos é que vão sofrer como nós (BP) \\
\hline
\end{tabular}

Figura 3 - Apresentação da percepção dos adolescentes acerca de como eles se veem frente ao tema álcool e outras drogas

Em suas narrativas estavam presentes os sentimentos e as emoções de um "olhar para dentro de si mesmo" (grifo dos autores), que expressavam expectativas de um futuro próximo, imaginando suas vidas como possíveis pais e mães de famílias, inseridos no contexto de álcool e outras drogas.

\section{Discussão}

As falas apresentadas acima expressam que o uso indevido de bebidas alcoólicas é considerado grave problema de saúde pública porque esse uso pode ser destruidor da vida e da família. Por outro lado, estando em situação de vulnerabilidade social, a pessoa pode se ater aos efeitos agradáveis da bebida, e correr risco maior para a dependência, principalmente se não possuir conhecimento suficiente $^{(2)}$.

A ideia de que o álcool possa ser inofensivo advêm da certeza de que sendo uma droga psicoativa, pode ser consumido sem causar nenhum problema à pessoa. No entanto, pode levar à dependência física e psíquica, dependendo da quantidade e frequência de consumo, podendo trazer inúmeras e graves consequências, tanto orgânicas como psicológicas e sociais, o que é tão grave quanto outras drogas, consideradas mais potentes ${ }^{(3)}$

Ainda no primeiro encontro, o facilitador do grupo focal, a exemplo de outros pesquisadores, levou pequenos textos, ou frases que abordavam os conceitos de álcool e outras drogas - objeto de estudo - como estratégias para facilitar e incrementar o debate.

As diferenças de opiniões constatadas nas falas dos adolescentes confirmam que a percepção é uma unidade autônoma e entidade universal de todo ser humano, que depende do espaço subjetivo e do contexto cultural.

No momento da fala dos adolescentes, quando os mesmos se referem a elementos balizadores como: origem étnica, história familiar, etapa do ciclo da vida em que se encontram e relações de gênero, estabelecidas no universo em que vive, para o processo de modelação da subjetividade do eu, são de extrema importância na formulação de conceitos que irão definir a postura desses adolescentes perante a vida ${ }^{(4)}$.

Em suas falas, os adolescentes revelaram as experiências de pessoas próximas que faziam uso de substâncias psicoativas e expressaram a sua percepção sobre o assunto. Mesmo estando no século XXI, observa-se que a discussão acerca do tema ainda suscita sentimentos negativos como sendo proibido mencionar, pois traz à tona vivências não positivas, portanto, é preferível afastar, repudiar, tornando muitas vezes diálogos a esse respeito um "tabu" (grifo dos autores) pela própria família.

Em síntese, esses argumentos podem ser agrupados como uma forma de desabafo, mostrando ainda haver pouco ou nenhum diálogo a respeito do assunto na família. A questão é mais abordada pela mãe que, muitas vezes, fala a respeito das drogas com o filho de forma fantasiosa, como alerta e proibição, o que também acontece muito com as questões relacionadas à sexualidade ${ }^{(5)}$

Assim sendo, a construção cultural para a questão do álcool e outras drogas no ambiente familiar é de extrema importância, pois muitos estudos revelam a influência das atitudes dos pais sobre os filhos, em que o maior consumo de álcool e história de alcoolismo entre os adolescentes acontece quando existe a história pregressa familiar para o uso de álcool. Assim, filhos de pais alcoólatras apresentam maiores problemas de comportamento quando comparados aos filhos de pais abstinentes de álcool. Isso sugere que o consumo de álcool dos pais poderia ser fator de risco para o desenvolvimento de dependência dos filhos ${ }^{(6-7)}$.

De acordo com os relatos, percebe-se que o uso de bebidas alcoólicas inicia-se precocemente, entre o início e meio da adolescência. Normalmente se dá com o grupo de amigos ou mesmo em casa, pois muitos adolescentes experimentaram álcool ainda na infância, oferecido pelos pais nas refeições, conforme descrito anteriormente. Para evitar que isso aconteça, é necessário que cada vez mais recursos sejam aplicados, a fim de minimizar esse grave problema de saúde pública ${ }^{(10)}$. 
É visível que a experimentação de bebidas alcoólicas com a família e o uso posterior com os amigos parecem estar incorporados ao comportamento do adulto. Em contrapartida, outro estudo mostrou que em famílias consumidoras regulares de bebidas alcoólicas, principalmente as de médio e alto teor alcoólico, os adolescentes não experimentavam bebida alcoólica com a família. Uma possível explicação para o fato seria que, para a família, as bebidas de alto teor alcoólico não sejam adequadas à experimentação de crianças ou adolescentes. Como membros dessas famílias utilizam o álcool de forma abusiva, os adolescentes não bebem com eles por não poderem consumir o mesmo tipo de bebida e a mesma quantidade que os adultos. Essas famílias tendem à intolerância de embriaguez entre seus adolescentes. Dessa forma, as famílias se contradizem quanto às regras por elas impostas ${ }^{(11)}$. Nesta investigação, foi nas experiências indiretas que os adolescentes formaram suas percepções acerca do tema.

Alguns estudos afirmam que, quando as regras estabelecidas pelos pais são claras, acerca do consumo de bebida alcoólica, conseguem atingir elevado grau de eficiência na prevenção do alcoolismo. Por outro lado, pais que não expressam normas reguladoras a respeito do álcool têm mais probabilidade de ter filhos que bebam abusivamente. A permissividade ou o interesse dos pais pelo consumo de álcool de seus filhos influencia os hábitos alcoólicos dos mesmos ${ }^{(12)}$.

O uso pesado de álcool é maior no gênero masculino em relação ao feminino; quanto à classe social nos estratos sociais A e B encontravam-se os maiores consumidores; os que faziam uso pesado de álcool apresentavam maior defasagem escolar. $\mathrm{O}$ estudo revelou também que os pais bebem muito mais que as mães ${ }^{(13)}$.

A média de idade, atualmente, para a primeira experimentação do álcool, tem ocorrido muito cedo, por volta dos 12 anos, o que é muito preocupante, pois quanto mais cedo se inicia o contato com o álcool maior é a probabilidade de que se estabeleça a dependência pela substância, além de ela ser a porta de entrada para o consumo de outra ${ }^{(14)}$.

Assim, a importância do ambiente e a estruturação familiar podem agir como possível fator protetor para o uso pesado de álcool, pois um estudo identificou o menor uso em adolescentes que, de certa forma, se sentiam apoiados e compreendidos pela família ${ }^{(15)}$. Fica explícito então que, certamente, o exemplo é o maior reforço para o aprendizado, e não apenas a teorização, e que os mesmos devem estar sempre alinhados.

\section{Considerações Finais}

Dentre os diferentes depoimentos encontrados verificou-se que a ideia de álcool e drogas e o maior contato desses adolescentes acontecem realmente no seio da família e com os amigos, e é perceptível como essa realidade os envolve de modo intenso.

Foi unânime a tristeza quando todos referiram ter perdido alguém por causa do álcool ou de outras drogas.
Essa construção é o resultado de multiplicidade de fatores históricos, sociais e culturais que integram a rede de significado social específico, possibilitando a manifestação de toda e qualquer expressão, conforme o papel encenado em cada ato.

O debate evidenciou como o entendimento do álcool e de outras drogas se dá pela maneira como esses adolescentes pensam e agem, que está relacionado com todos os aspectos de suas vidas. Como seres culturais como o agir, pensar e sentir, eles expressam os significados de acordo com a sua visão de mundo, revelada em concordância com a rede de significados específicos ao grupo a que pertencem. Por isso, sua manifestação está representada nos modelos subjetivos do "eu me vejo".

Conclui-se, portanto, que a percepção desses adolescentes acerca do álcool e outras drogas não acontece de forma ilusória, fantasiosa, mas pautada em acontecimentos intrínsecos à família, que marcam a presente e, muito provavelmente, marcarão a futura trajetória de vida dos mesmos.

A questão do álcool e drogas entre adolescentes está inserida no contexto da família que, uma vez não estando bem estruturada, com diálogo, exemplo e limite, pode se tornar o agente causador de grande desgaste emocional em suas vidas. Portanto, os componentes relacionados à família devem ser considerados para a implementação de ações educativas para esse grupo etário, visando mudanças de comportamento relacionado ao consumo de drogas.

\section{Agradecimentos}

Ao Programa Institucional de Bolsas de Iniciação Cientifica - (Pibic), do Conselho Nacional de Desenvolvimento Científico e Tecnológico (CNPq).

\section{Referências}

1. Galduróz JCF, Carlini EA, Noto AR, Napo SA. I Levantamento domiciliar nacional sobre o uso de drogas psicotrópicas. Parte A: estudo envolvendo as 24 maiores cidades do estado de São Paulo. São Paulo: CEBRID/ UNIFESP; 2000.

2. Alves R, Kossobudsky AL. Caracterização dos adolescentes internados por álcool e outras drogas na cidade de Curitiba. Interação Psicol. 2002;6(1):65-79.

3. Oetting ER, Donnermeyer JF. Primary socialization theory: the etiology of drug use and deviance. Part I. Substance Use Misuse. 1998;33(4):995-1026.

4. Ferrrari DCA. Definição de abuso na infância e na adolescência. In: Ferrari DCA, Vecina TCC, organizadores. O fim do silêncio da violência familiar. São Paulo: Ágora; 2002. 5. Osório, LC. Família hoje. Porto Alegre: Artes Médicas; 1996.

6. Levisky DL. adolescência: pelos caminhos da violência, a psicanálise na prática social. São Paulo: Casa do Psicólogo; 1998.

7. Melo ZM de, Caldas MT, Carvalho MMC, Lima ATde. Família, álcool e violência em uma comunidade da cidade do Recife. Psicol Estudo. 2005;10(2):201-8. 
8. Bom Meihy JCS, Holanda F. História Oral: como fazer como pensar. São Paulo: Contexto; 2007.

9. Merleau-Ponty M. O visível e o invisível (1964). Brasil: Editora Perspectiva; 2003.

10. World Health Organization: Assist Working Group. The alcohol, smoking and substance involvement screening test (ASSIST): development, reliability and feasibility. Addiction. 2002;97:1183-94.

11. Matheus MCC, Fustinoni SM. Pesquisa Qualitativa em Enfermagem. São Paulo: Médica Paulista; 2006.

12. Cardenal CA, Adell MN. Factors associated with problematic alcohol consumption in schoolchildren. J Adolescent Health. 2000;27:425-33.

13. Ramos SdePE, Bertolote JM. Alcoolismo hoje. Porto Alegre: Artes Médicas; 1997.

14. Débus M. Manual para excelência en la investigacion mediante grupos focales. Washington: Academy for Educational Development; 1997.

15. Ressel LB, Gualda DMR, Gonzáles RMB. Grupo focal como uma estratégia para coletar dados de pesquisa em enfermagem. Int $\mathbf{J}$ Qual Methods Spring [periódico na Internet]. 2002 [citado 21 jul 2010];1(2):1-29. Disponível em: http://www.ualberta.ca/ iiqm/backissues/1_2Final/ pdf/ressel.pdf

\section{Como citar este artigo:}

Pereira MO, Silva SS, Oliveira MAF, Vargas D, Colvero LA, Leal BMML. A percepção dos adolescentes acerca do álcool e outras drogas no contexto familiar. SMAD, Rev. Eletrônica Saúde Mental Álcool Drog. (Ed. port.). set.-dez. 2011 [acesso: ;7(3):148-54. Disponível em:

mês abreviado com ponto 